\title{
Improved adherence with once-daily versus twice-daily dosing of mometasone furoate administered via a dry powder inhaler: a randomized open-label study
}

\author{
David Price ${ }^{1 *}$, Anne Robertson ${ }^{2}$, Kevin Bullen ${ }^{3}$, Cynthia Rand ${ }^{4}$, Rob Horne ${ }^{5}$, Heribert Staudinger ${ }^{6}$
}

\begin{abstract}
Background: Poor adherence with prescribed asthma medication is a major barrier to positive treatment outcomes. This study was designed to determine the effect of a once-daily administration of mometasone furoate administered via a dry powder inhaler (MF-DPI) on treatment adherence compared with a twice-daily administration.

Methods: This was a 12-week open-label study designed to mimic an actual clinical setting in patients $\geq 12$ years old with mild-to-moderate persistent asthma. Patients were randomized to receive MF-DPI $400 \mu \mathrm{g}$ once-daily in the evening or MF-DPI $200 \mu \mathrm{g}$ twice-daily. Adherence was assessed primarily using the number of actual administered doses reported from the device counter divided by the number of scheduled doses. Self-reports were also used to determine adherence. Health-related quality of life, healthcare resource utilization, and days missed from work or school were also reported.
\end{abstract}

Results: 1233 patients were randomized. The mean adherence rates, as measured by the automatic dose counter, were significantly better $(P<0.001)$ with MF-DPI $400 \mu$ g once-daily in the evening (93.3\%) than with MF-DPI 200 $\mu \mathrm{g}$ twice-daily (89.5\%). Mean adherence rates based on self-reports were also significantly better $(P<0.001)$ with MF-DPI $400 \mu \mathrm{g}$ QD PM (97.2\%) than with MF-DPI $200 \mu \mathrm{g}$ twice-daily (95.3\%). Adherence rates were lower in adolescents (12-17 years old). Health-related quality of life improved by $20 \%$ in patients using MF-DPI once-daily in the evening and by $14 \%$ in patients using MF-DPI twice-daily. Very few $(<8 \%)$ patients missed work/school.

Conclusion: Mean adherence rates were greater with a once-daily dosing regimen of MF-DPI than with a twicedaily dosing regimen.

This trial was completed prior to the ISMJE requirements for trial registration.

\section{Background}

It is well established that inhaled corticosteroid (ICS) therapy is the most effective treatment for patients with persistent asthma[1,2]. Unfortunately, studies have shown adherence with prescribed ICS therapy is poor, with adherence rates generally thought to range from $30 \%-70 \%$ [3-6]. Low adherence is not only a major barrier to achieving positive treatment outcomes in asthma management, but may also be associated with an

\footnotetext{
* Correspondence: david@respiratoryresearch.org

'Centre of Academic Primary Care, University of Aberdeen, Foresterhill
} Health Centre, Aberdeen, UK increased risk of death due to asthma[7] and increased health care costs, primarily through overuse of urgent care, hospitalization, and unnecessary physician visits $[5,8,9]$.

Although further investigation on the effects of oncedaily dosing on ICS treatment adherence under more controlled settings are needed, better adherence has been observed in asthma[10] and other disease treatments with once-daily dosing regimens than with twicedaily regimens [11-13]. A case-control study by Guest et al.[10] found that patients on twice-daily asthma treatments who were switched to once-daily treatments were 
better compliers than those switched to another twicedaily treatment. In addition, primary care management costs were lower in patients who showed high adherence after switching to once-daily treatment.

Mometasone furoate administered via a dry powder inhaler (MF-DPI) has been shown to be effective in treating asthma, as shown in comparative studies with other ICSs [14-18]. Although early studies of MF-DPI in mild and moderate asthma patients evaluated twicedaily dosing regimens, $[14,19]$ more recent studies have demonstrated the comparability of MF-DPI $400 \mu \mathrm{g}$ once-daily in the morning to MF-DPI $200 \mu \mathrm{g}$ twice-daily $[20,21]$ and the high efficacy of once-daily dosing in the evening [22-25]. However, it should be noted that clinical studies assessing adherence are often complicated by a variety of factors, such as greater adherence rates due to close patient monitoring, which results in adherence rates not typical of clinical practice[13,26].

The primary objective of this study was to determine the effect of once-daily versus twice-daily dosing of MFDPI on treatment adherence in a study designed to mimic the actual clinical setting.

\section{Methods}

\section{Patient Population}

This multicenter study (143 sites in the United Kingdom) enrolled adolescents and adults aged 12 years or older with mild-to-moderate persistent asthma, and a diagnosis of asthma for at least 1 year. The study had institutional review board approval at all sites, and all patients provided informed consent before any study procedures were conducted. The first visit date was February 5, 2003, and the latest visit/contact date was February 26, 2004. Eligible patients had been treated with either beclomethasone dipropionate (BDP) hydrofluoroalkane $(\leq 500 \mu \mathrm{g} / \mathrm{d})$ or BDP chlorofluorocarbon $(\leq 1000$ $\mu \mathrm{g} / \mathrm{d}$ ) for $\geq 12$ weeks, and had a stable BDP dosing regimen for $\geq 4$ weeks immediately before study entry. The inclusion of patients who used BDP as their prior ICS therapy was justified because BDP was the ICS prescribed most commonly in the UK when the study was conducted, thereby providing a patient population as large and homogeneously-treated as possible. Eligible patients had no clinically significant disease that would interfere with study evaluations, and female patients of childbearing potential were required to use medically accepted birth control. Patients who required ventilator support for respiratory failure due to asthma within the previous 5 years or were hospitalized within the previous 3 months because of asthma were ineligible.

\section{Study Protocol}

This was a 12-week, open-label study designed to mimic an actual clinical setting. Visits took place every 4 weeks. Patients were randomized to receive either MF-
DPI $400 \mu \mathrm{g}$ once-daily in the evening or MF DPI $200 \mu \mathrm{g}$ twice-daily from inhalers measuring $220 \mu \mathrm{g} /$ actuation and delivering $200 \mu \mathrm{g} /$ inhalation. Assessments were made at baseline, and weeks 4,8 , and 12 . Patients were instructed in inhaler use and peak flow measurement to demonstrate proficiency and received salbutamol for rescue medication. Optional diary cards were provided to record adverse events (AEs), use of rescue medication, and changes in concomitant medication between visits. Completed diary comment cards were reviewed at all subsequent visits. Following increases in asthma symptoms from baseline, patients used the peak flow meter to obtain an objective measure of asthma worsening. Daily use of the peak flow meter was not required to more closely mimic real-life practice. Patients were also instructed to follow an asthma action plan based on their personal best peak flow at the first visit. If peak flow was $<75 \%$ personal best for 2 consecutive days, the patient was required to consult the investigator. Recommended clinical practice guidelines were also provided to investigators.

\section{Primary Evaluation}

Adherence was calculated as the number of administered doses (as determined by device counter number) times 100 divided by the number of scheduled doses. Data were not included for analysis if invalid (eg, gross misuse of device, missing treatment end dates, or device malfunction). Examples of gross misuse of the device included failure to twist the cap when opening/closing the inhaler, or removing and replacing the inhaler cap more than once without taking a dose. If a device was not returned, it was assumed to have been unused.

\section{Secondary Evaluations}

Secondary evaluations included measurements of adherence based on the patients' or their guardians' reports of adherence, regardless of the actual counter readings. The physician's assessment of a therapeutic response was documented at all visits. Health-related quality of life (HRQOL) was assessed using the Integrated Therapeutics Group Asthma Short Form (ITG-ASF), a brief and reliable disease-specific questionnaire[27]. For this study, the ITG-ASF was administered at baseline and week 12. The ITG-ASF does not have a derivation of total score for children, therefore, only HRQOL data obtained from subjects at least 16 years old are reported. Healthcare resource utilization and the number of days missed from work or school were recorded at all visits.

\section{Safety Evaluation}

Safety assessments included reporting of AEs at all visits. An abbreviated physical exam and vital signs (heart, lungs, weight, blood pressure, pulse, and breath rates) were performed on visits 1 and 4. An evaluation of asthma worsening was performed at all visits, with asthma worsening being defined as an increased use of 
rescue medication ( $>12$ inhalations on 2 consecutive days), a decrease in peak flow of $>25 \%$ on 2 consecutive days, or clinical asthma exacerbations (unscheduled doctor's visit, hospitalization, ER visit, and/or use of additional asthma medications other than short-acting $\beta$-agonists).

\section{Statistical Analyses}

A total of 1300 patients, or 650 per treatment group, were targeted for inclusion in this study, allowing a $90 \%$ power to detect a difference of at least $10 \%$ between distributions of adherence rates. The study was not powered to test differences in mean adherence. A sample of this size also allowed a sub-group analysis, with a $90 \%$ power to detect positive correlations of more than 0.15 between the level of adherence and the total ITG-ASF within each group (0.05 significance level). The Kolmogorov-Smirnov test was used to determine the significance of observed differences in the distribution of adherence rates between the 2 treatment groups. The Pearson correlation coefficient was used to analyze the correlation between adherence and changes in the ITG-ASF score. The chi-square test was used to analyze health care utilization and number of missed days of school/work. An analysis of variance (ANOVA) was used to extract sources of variation by treatment and center.

\section{Results}

Patients

A total of 1233 patients were randomized to treatment; 611 patients in the MF-DPI $400 \mu \mathrm{g}$ once-daily group and 622 patients in the MF-DPI $200 \mu \mathrm{g}$ twice-daily group (Figure 1). The primary analysis of adherence excluded subjects with invalid data, subjects missing treatment end dates, and subjects who reported device issues. Adherence data based on the device counter was analyzed for 557 patients in the MF-DPI $400 \mu \mathrm{g}$ oncedaily group and 578 patients in the MF-DPI $200 \mu \mathrm{g}$ twice-daily group. Similar proportions of subjects in the 2 treatment groups returned all 6 canisters of study medication: $92.0 \%(469 / 510)$ in the MF-DPI $400 \mu \mathrm{g}$ once-daily group and $90.7 \%(478 / 527)$ in the MF-DPI $200 \mu \mathrm{g}$ twice-daily group. No statistical differences were present between the randomized groups at baseline in age, sex, race, and weight, or in duration of disease (seasonal or allergic rhinitis or asthma). Baseline demographics are shown in Table 1.

\section{Primary Endpoint (Adherence)}

The primary endpoint of adherence as measured by device counter was $93.3 \%$ (95\% CI: 91.6-94.9) for the once-daily group and $89.5 \%$ (95\% CI: 88.1-90.8) for the twice-daily group; the maximum difference in distribution of adherence rates results was significant at $P<$ 0.001 (Figure 2). As measured by patient self-reports, adherence was $97.2 \%$ (95\% CI: 96.4-97.9) for the once- daily group and $95.3 \%$ (95\% CI: 94.4-96.2) for the twicedaily group, and the difference in distribution of the adherence results was significant at $P<0.001$ (Figure 2). In the subgroup of patients who received and returned all 6 canisters of study medication, adherence was $96.4 \%$ (95\% CI: 95.5-97.3) for the once-daily group ( $n=469)$, and $91.8 \%$ (95\% CI: 91.0-92.7) for the twice-daily group (n $=478 ; P<0.001)$. Adherence was numerically lower for $12-18$ year olds (once-daily group $=80.8 \%$ [95\% CI: 64.1-97.5]), twice-daily group $=87.3 \%$ [95\% CI: 81.2 $92.4]$ ); these patients comprised only $3 \%$ of the population, and statistical analysis was not done because there were very few patients in this subgroup. The rates of adherence for female and male patients were similar to each other and to the overall population.

\section{Secondary Endpoints}

Using 2-way ANOVA with treatment and site effects, 52\% of individual patients showed improvement in the physician's evaluation of therapeutic response on a scale of 1-5 from baseline, with 1 representing much improved and 5 representing much worse $(P=$ not significant; Figure 3$)$. With regard to HRQOL as measured by ITG-ASF scores (assessed in subjects at least 16 years of age), both groups improved relative to baseline (Figure 4). No significant correlation existed between HRQOL and adherence. However, there was a numerically greater increase in HRQOL in the once-daily group (20\%) relative to the twice-daily group (14\%), although the difference was not statistically significant $(P=0.08)$. Regarding healthcare utilization, few patients had missed days of work or school (once-daily group $=9$; twice-daily group $=10$ ) or unscheduled health visits (once-daily group $=37$; twice-daily group $=33$ ). No significant difference was seen between treatment groups $(P \geq 0.48)$.

\section{Safety Evaluation}

The nature and occurrence of AEs were similar to those reported in other studies of ICS [28-30]. AEs for the most part were not considered treatment related, and were mild-to-moderate in severity (Table 2). Only 6 patients reported severe treatment-related AEs; 1 patient each with mouth ulceration and oral candidiasis in the MF-DPI 400 $\mu$ g once-daily group, and 1 patient each with headache, tongue disorder, oral candidiasis, and hypoglycemia in the MF-DPI $200 \mu \mathrm{g}$ twice-daily group. Fifty-five patients (23 in the once-daily group and 32 in the twice-daily group) discontinued treatment owing to AEs, and were not analyzed. An additional 38 patients had treatment interrupted owing to AEs. Two patient deaths were reported (1 due to cardiorespiratory arrest and 1 due to lung carcinoma); neither was considered treatment related.

\section{Discussion}

Mean adherence rates, as measured by the automatic dose counter, were found to be significantly better for a 


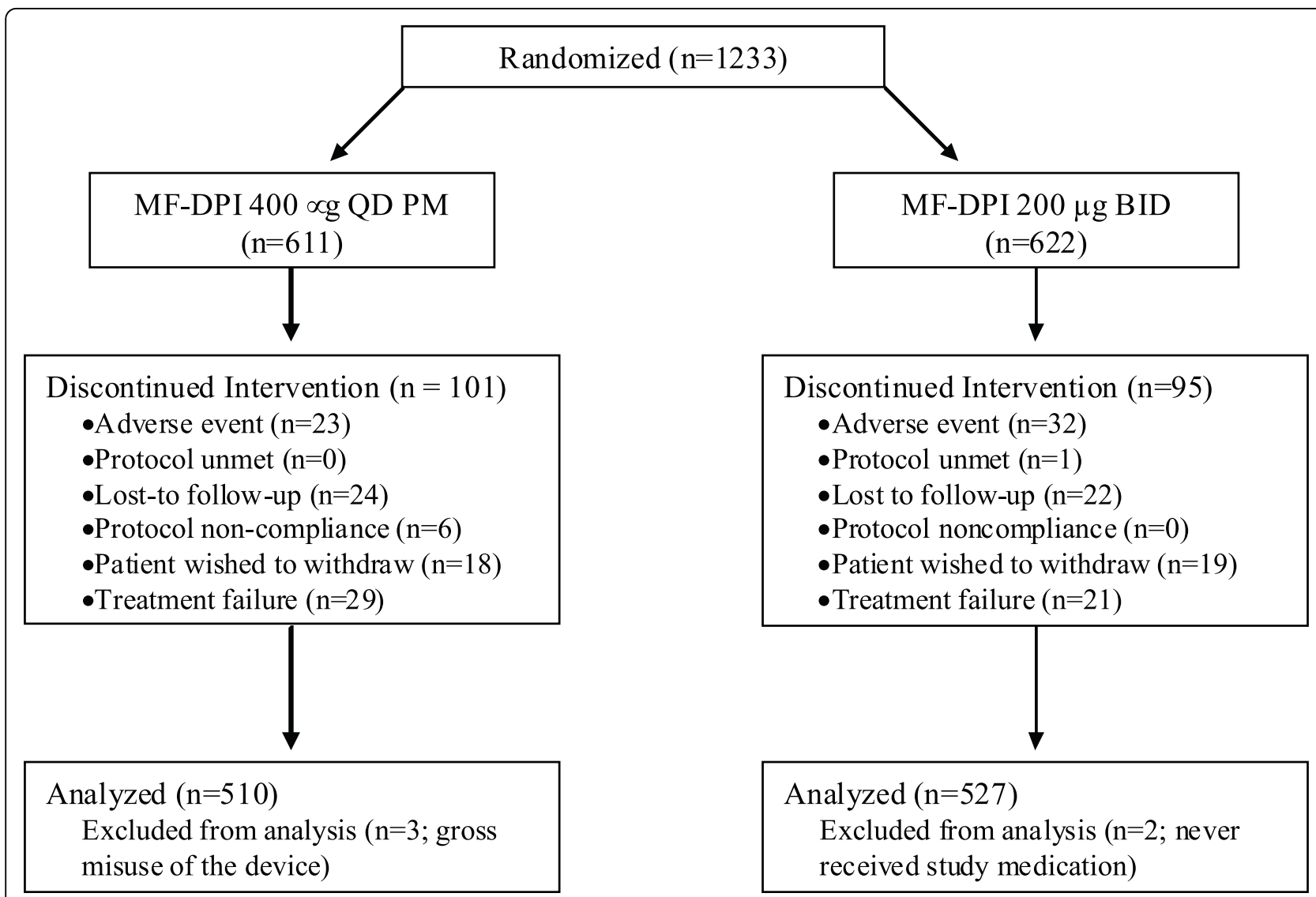

Figure 1 Subject Disposition. MF-DPI = mometasone furoate administered via a dry powder inhaler.

once-daily regimen of MF-DPI compared to twice-daily administration. Once-daily treatment with MF-DPI also significantly improved mean adherence rates based on patient self-reports compared with twice-daily MF-DPI, as well as mean adherence rates based only on those patients who received and returned all 6 canisters of study medication.

Despite the significant differences in mean adherence, we found no significant differences in clinical outcomes. This is likely due to the unusually high rates of adherence observed in both study groups (89\%-93\%). The adherence rates in this study are much higher than the rates previously reported in the literature (30\% to $70 \%$ ), $[5,6]$ and may have been influenced by the constraints of the clinical trial in terms of attention and study participants. Direct interaction between physicians and asthma patients (or their parents/caregivers) has been shown to improve adherence. In one study, a treatment group receiving direct feedback from clinicians had an adherence rate of approximately $60 \%$ at the first visit, which then increased and remained above $70 \%$ at each weekly visit for the duration of the 10 -week study. In the control group receiving usual asthma care, adherence declined from approximately $50 \%$ at the first weekly visit to $<30 \%$ at the final weekly visit[4]. In addition, patients who volunteer to participate in a study may be more willing to comply with a treatment regimen.

This study was designed to prevent some of these issues. Patients were not informed that device dose counts were checked at each visit. The study also tried to decrease aspects of a clinical study that would promote adherence and tried to mimic asthma management in a typical clinical practice. Doctor visits were limited to once a month, and patients were not required to keep daily records of symptoms or peak flow. In addition, in accordance with clinical practice guidelines, [1,2] patients were given an "Asthma Action Plan" to help guide them in self-managing their symptoms.

A limitation of this study may be its duration. Treatment adherence in clinical trial settings does not typically reflect normal rates of adherence until a more prolonged period has passed[31]. One long-term study of children and adolescents (ages 7-16 y) with mild asthma treated with once- or twice-daily doses of ICS found that adherence rates significantly declined following 3 months of treatment and continued to decline by more than $50 \%$ in both treatment groups after 9 months 


\begin{tabular}{|c|c|c|}
\hline & $\begin{array}{c}\text { MF-DPI } 400 \mu \mathrm{g} \text { QD PM } \\
(\mathrm{n}=611)\end{array}$ & $\begin{array}{c}\text { MF-DPI } 200 \mu \mathrm{g} \text { BID } \\
(\mathrm{n}=622)\end{array}$ \\
\hline Mean age, y & 50.9 & 50.2 \\
\hline \multicolumn{3}{|l|}{ Patients by age, n (\%) } \\
\hline 12 to $<18$ y & $21(3)$ & $22(4)$ \\
\hline 18 to $<65 y$ & $444(73)$ & $465(75)$ \\
\hline$\geq 65$ y & $146(24)$ & $135(22)$ \\
\hline \multicolumn{3}{|l|}{ Sex } \\
\hline Women/men & $338 / 273$ & $357 / 265$ \\
\hline \multicolumn{3}{|l|}{ Race } \\
\hline White/nonwhite & $607 / 4$ & $615 / 7$ \\
\hline \multirow[t]{2}{*}{ Mean body weight, kg } & 77.3 & 76.7 \\
\hline & $n=599$ & $n=614$ \\
\hline \multirow[t]{2}{*}{ Mean duration of SAR, y } & 17.2 & 19.2 \\
\hline & $n=238$ & $n=235$ \\
\hline \multirow[t]{2}{*}{ Mean duration of PAR, y } & 19.7 & 20.9 \\
\hline & $n=163$ & $n=164$ \\
\hline \multirow[t]{2}{*}{ Mean duration of asthma, y } & 16.4 & 16.2 \\
\hline & $n=611$ & $n=622$ \\
\hline
\end{tabular}

$\mathrm{BID}=$ twice-daily; MF-DPI = mometasone furoate administered via a dry powder inhaler; $\mathrm{PAR}=$ perennial allergic rhinitis; $\mathrm{QD}$ PM = once-daily in the evening; SAR $=$ seasonal allergic rhinitis.

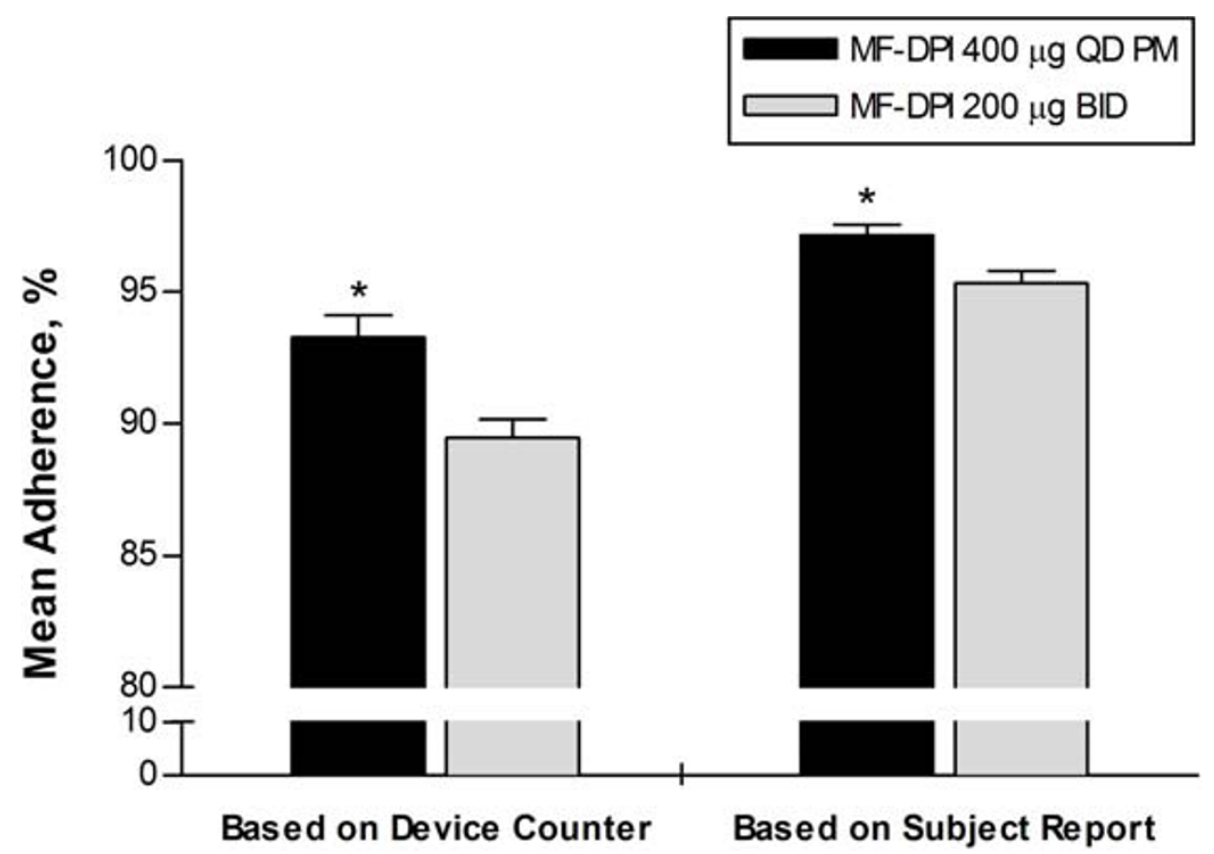

Figure 2 Mean adherence to treatment. Adherence was calculated as administered doses divided by scheduled doses $\times 100$, as measured by dose counter and patient self-report. Error bars represent standard error of the mean. ${ }^{*} P<0.001$. BID $=$ twice-daily; MF-DPI $=$ mometasone furoate administered via a dry powder inhaler; $Q D=$ once-daily. 


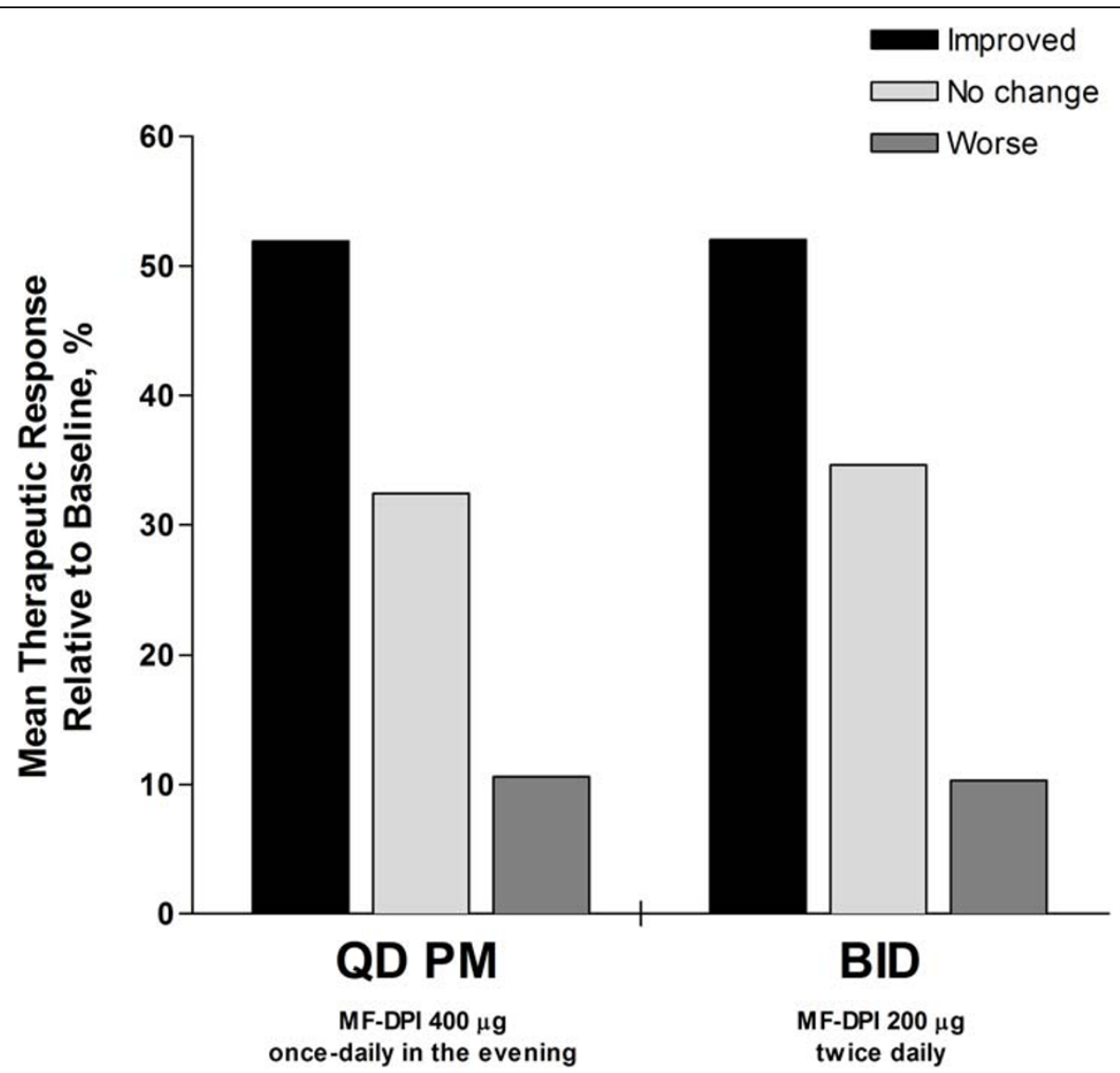

Figure 3 Physician's evaluation of therapeutic response. Response expressed as mean relative to baseline. $P=$ not significant. MF-DPI $=$ mometasone furoate administered via a dry powder inhaler.

[31]. Thus, it is possible that given a longer duration, the adherence rates observed in this study would decrease to lower levels. Furthermore, this study did not use direct measures of adherence, which are not practical or reliable for large numbers of patients in ordinary settings. It is not possible to document whether patients were actually taking their medication correctly or following their dosing regimen. The patients may have taken multiple doses at the same time, or patients may have actuated their inhaler but not taken the medication. In addition, since patients were not required to keep daily diary records, their self-reports were based largely on memory, which may have resulted in erroneous adherence estimates.

The literature is lacking clear documentation on the impact of once- vs twice-daily dosing. However, reliable measurements of medication use were obtained in a study that evaluated adherence by patients with mild asthma randomized to treatment with oral montelukast $10 \mathrm{mg}$ once-daily $(\mathrm{n}=189)$ or inhaled fluticasone propionate $88 \mu \mathrm{g}$ twice-daily $(\mathrm{n}=191)$ [32]. The montelukast pill boxes and fluticasone inhalers used in the study had electronic monitoring devices to record medication use continuously over 12 weeks of placebo-controlled double-blind treatment and 36 weeks of open-label treatment with no placebo. Adherence rates with oncedaily montelukast and twice-daily fluticasone were $77.5 \%$ and $70.2 \%$, respectively $(P<0.0001)$, during double-blind treatment and $71.4 \%$ and $63.9 \%$, respectively $(P=0.001)$, during open-label treatment. Although adherence rates in the study were less than prescribed, it was found that adherence with once-daily treatment was superior to adherence with twice-daily treatment. This difference could be related to the fact that montelukast is an oral medication and fluticasone is an inhaled medication.

Despite limitations of the present study, the observed efficacy results suggest that patients were taking their medication and that their asthma was more adequately treated than it had been prior to randomization. Both treatment groups showed improved HRQOL, and over half of all patients in both treatment groups were rated as having an improved therapeutic response from baseline. Very few patients had unscheduled office or home 


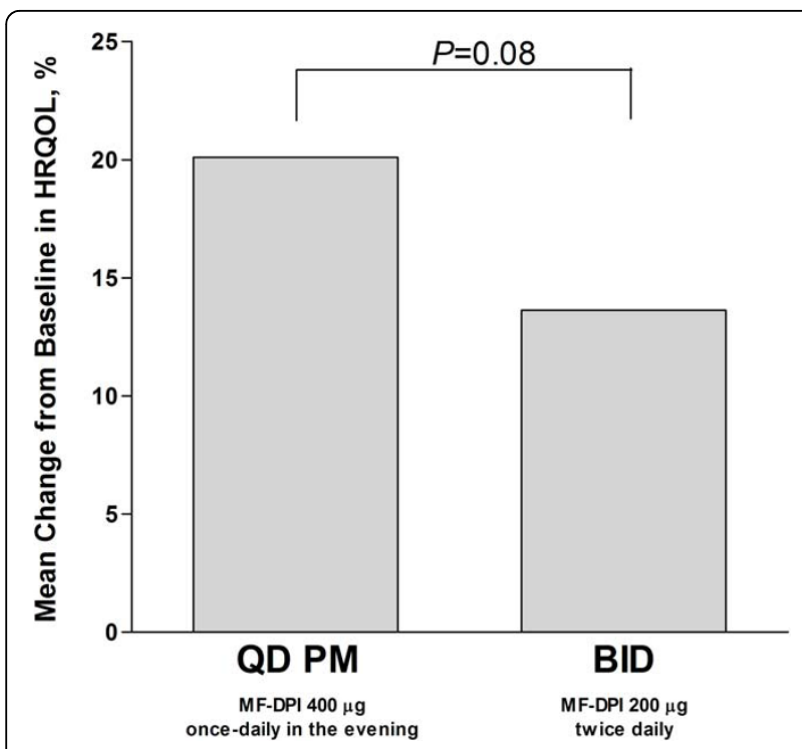

Figure 4 Mean percent change in HRQOL. Changes from baseline in HRQOL were measured by ITG-ASF scores in subjects $\geq 16$ years of age. $\mathrm{HRQOL}=$ health-related quality of life; ITG-ASF = Integrated Therapeutics Group-Asthma Short Form; MF-DPI = mometasone furoate administered via a dry powder inhaler; QD = once-daily.

visits or reported missed days from work or school. The differences in adherence between the once-daily and twice-daily groups were statistically significant, yet they were small and not correlated with improvements in HRQOL. Moreover, once-daily dosing in adolescents was associated with numerically lower adherence than twice-daily dosing, although this difference was not statistically significant.

Asthma therapy is complex, and treatment dosing frequency is one of many factors that affect adherence.
Both groups in the present study had high rates of adherence, which suggests that factors including the physician-patient relationship, medical costs, and patient beliefs regarding illness and medication strongly influence adherence in clinical practice[33,34]. According to the model proposed by Horne et al,[33] treatment adherence is related to a patient's perception of illness. Strong correlations have been observed between (1) nonadherence and patients who believed treatment medication was unnecessary or had concerns of adverse effects and (2) greater adherence and patients who believed their asthma was of greater severity[33]. It is essential to individualize therapy to meet patient needs by identifying nonadherence and the causes of nonadherence for individual patients, as recommended in a recent paper by the International Primary Care Respiratory Group.[35]

One indication for prescribing once-daily asthma therapy is for patients who are likely to experience difficulties with twice-daily therapy. It is clear that most patients randomized to twice-daily treatment in the present study did not find this regimen to be a barrier to adherence, although overall adherence rates in clinical practice appear to be significantly lower than adherence rates in this trial. Further studies are needed to determine the degree to which twice-daily dosing might erode adherence over time, and to measure the effects of switching to a once-daily regimen for those patients who find that twice-daily therapy is a barrier to adherence. Although for some patients it is also possible that dosing frequency may have an impact on treatment efficacy, given that a once-daily medication has only one trough per day, whereas a twice-daily medication has two troughs per day. In the present study, however, the once- and twice-daily doses of MF-DPI had similar efficacy.

Table 2 Incidence of Treatment-Related AEs Reported by $\geq 1 \%$ of Patients

\begin{tabular}{|c|c|c|}
\hline & $\begin{array}{c}\text { MF-DPI } 400 \mu \mathrm{g} \text { QD PM } \\
(\mathrm{n}=611)\end{array}$ & $\begin{array}{c}\text { MF-DPI } 200 \mu \mathrm{g} \text { BID } \\
(\mathrm{n}=622)\end{array}$ \\
\hline Patients reporting any $A E, n(\%)$ & $85(14)$ & $109(18)$ \\
\hline Headache & $10(2)$ & $12(2)$ \\
\hline Dysphonia & $3(<1)$ & $9(1)$ \\
\hline Mouth dry & $12(2)$ & $11(2)$ \\
\hline Mouth ulceration & $5(1)$ & $1(<1)$ \\
\hline Candidiasis, oral & $9(1)$ & $16(3)$ \\
\hline Pharyngitis & $16(3)$ & $15(2)$ \\
\hline Upper respiratory tract infection & $5(1)$ & 0 \\
\hline Cough & $2(<1)$ & $6(1)$ \\
\hline Hoarseness & $4(1)$ & $5(1)$ \\
\hline Throat dry & $11(2)$ & $3(<1)$ \\
\hline Rash & 0 & $4(1)$ \\
\hline
\end{tabular}

$\mathrm{AE}$ = adverse event; $\mathrm{BID}$ = twice-daily; MF-DPI = mometasone furoate administered via a dry powder inhaler; $\mathrm{QD}$ PM = once-daily in the evening. 


\section{Conclusion}

Overall adherence to treatment with mometasone furoate dry powder inhaler was very high in this study, with a statistically greater mean adherence rate using a oncedaily dosing regimen versus a twice-daily dosing regimen.

\section{Abbreviations}

AE: adverse event; ANOVA: analysis of variance; BDP: beclomethasone dipropionate; BID: twice daily; HRQOL: health-related quality of life; ICS: inhaled corticosteroid; ITG-ASF: Integrated Therapeutics Group Asthma Short Form; MF-DPI: mometasone furoate administered via a dry powder inhaler; QD PM: once-daily in the evening.

\section{Acknowledgements}

This study was supported by Schering Corp., a division of Merck \& Co. Editorial and medical writing assistance was provided by Ken Kauffman, BSC at Complete Publication Solutions, LLC; this support was funded by Schering Corp., a division of Merck \& Co. The study sponsor was involved in the study design, as well as the analysis and interpretation of the data. The authors made the final decision to submit the manuscript.

\section{Author details}

${ }^{1}$ Centre of Academic Primary Care, University of Aberdeen, Foresterhill Health Centre, Aberdeen, UK. ${ }^{2}$ Barrhead Health Centre, Barrhead, UK. ${ }^{3}$ The Avenue Surgery, Wiltshire, UK. ${ }^{4}$ Department of Medicine, Johns Hopkins University, Baltimore, MD, USA. ${ }^{5}$ The School of Pharmacy, University of London, London, UK. 'Schering-Plough Research Institute, Kenilworth, NJ, USA.

\section{Authors' contributions}

Drs. DP, AR, KB, CR, and $\mathrm{RH}$ contributed to the acquisition, analysis, and interpretation of the data. Drs. DP, $\mathrm{CR}$, and $\mathrm{RH}$ contributed to the design of the study. Dr. HS contributed to the design of the study and interpretation of the results. All authors critically revised the manuscript for intellectual content and approved the final version.

\section{Competing interests}

Dr. Price or his team have received grants and research support from UK National Health Service, Altana Pharma, AstraZeneca, Boehringer Ingelheim, GlaxoSmithKline, Merck, Sharpe and Dohme, Novartis, Pfizer, Schering Corp. a division of Merck \& Co., and Teva; has consultant arrangements with Boehringer Ingelheim, GlaxoSmithKline, Merck generics, Merck, Sharpe and Dohme, Novartis, Schering Corp., a division of Merck \& Co., and Teva; and has spoken for Altana Pharma, Boehringer Ingelheim, GlaxoSmithKline, Merck, Sharpe and Dohme, Pfizer, and Schering Corp., a division of Merck \& Co., Dr. Robertson declares no competing interests. Dr. Bullen declares no competing interests. Dr. Rand has served on the Schering-Plough Respiratory Leadership Council and on the Merck Childhood Asthma Network advisory board. Dr. Horne has received grants from Gilead Life Sciences and Hayward Medical Communications/Shire Pharmaceuticals, and has consulted for various pharmaceutical companies. He is an officer of the University of London, School of Pharmacy. Dr. Staudinger is an employee and has stock and stock options for Schering Corp., a division of Merck \& Co.

Received: 8 May 2009

Accepted: 5 January 2010 Published: 5 January 2010

\section{References}

1. Global Strategy for Asthma Management and Prevention. http://www. ginasthma.com/Guidelineitem.asp??|1=2\&|2=1\&intld $=60$.

2. British guideline on the management of asthma: revised edition. http:// www.brit-thoracic.org.uk/Clinicallnformation/Asthma/AsthmaGuidelines/ tabid/83/Default.aspx.

3. Chmelik F, Doughty A: Objective measurements of compliance in asthma treatment. Ann Allergy 1994, 73(6):527-532.

4. Onyirimba F, Apter A, Reisine S, Litt M, McCusker C, Connors M, ZuWallack R: Direct clinician-to-patient feedback discussion of inhaled steroid use: its effect on adherence. Ann Allergy Asthma Immunol 2003, 90(4):411-415.

5. Bender $B$, Milgrom $H$, Rand $C$ : Nonadherence in asthmatic patients: is there a solution to the problem?. Ann Allergy Asthma Immunol 1997, 79(3):177-185.

6. Bender $B$, Milgrom $H$, Apter $A$ : Adherence intervention research: what have we learned and what do we do next?. J Allergy Clin Immunol 2003, 112(3):489-494.

7. Suissa S, Ernst P, Benayoun S, Baltzan M, Cai B: Low-dose inhaled corticosteroids and the prevention of death from asthma. N Engl J Med 2000, 343(5):332-336.

8. Bender $B G$, Rand C: Medication non-adherence and asthma treatment cost. Curr Opin Allergy Clin Immunol 2004, 4(3):191-195.

9. Stempel DA, Roberts CS, Stanford RH: Treatment patterns in the months prior to and after asthma-related emergency department visit. Chest 2004, 126(1):75-80.

10. Guest JF, Davie AM, Ruiz FJ, Greener MJ: Switching asthma patients to a once-daily inhaled steroid improves compliance and reduces healthcare costs. Prim Care Respir J 2005, 14(2):88-98.

11. Claxton AJ, Cramer J, Pierce C: A systematic review of the associations between dose regimens and medication compliance. Clin Ther 2001, 23(8):1296-1310.

12. Iskedjian M, Einarson TR, MacKeigan LD, Shear N, Addis A, Mittmann N, llersich AL: Relationship between daily dose frequency and adherence to antihypertensive pharmacotherapy: evidence from a meta-analysis. Clin Ther 2002, 24(2):302-316.

13. Osterberg L, Blaschke T: Adherence to medication. N Engl J Med 2005, 353(5):487-497.

14. Nathan RA, Nayak AS, Graft DF, Lawrence M, Picone FJ, Ahmed T, Wolfe J, Vanderwalker ML, Nolop KB, Harrison JE: Mometasone furoate: efficacy and safety in moderate asthma compared with beclomethasone dipropionate. Ann Allergy Asthma Immunol 2001, 86(2):203-210.

15. Bousquet J, D'Urzo A, Hebert J, Barraza CH, Boulet LP, Suarez-Chacon R, Harnest U, Lundback B, Martinez Morales G, Nieminen MM, et al: Comparison of the efficacy and safety of mometasone furoate dry powder inhaler to budesonide Turbuhaler. Eur Respir J 2000, 16(5):808-816.

16. O'Connor B, Bonnaud G, Haahtela T, Luna JM, Querfurt H, Wegener T, Lutsky BN: Dose-ranging study of mometasone furoate dry powder inhaler in the treatment of moderate persistent asthma using fluticasone propionate as an active comparator. Ann Allergy Asthma Immunol 2001, 86(4):397-404.

17. Corren J, Berkowitz R, Murray JJ, Prenner B: Comparison of once-daily mometasone furoate versus once-daily budesonide in patients with moderate persistent asthma. Int J Clin Pract 2003, 57(7):567-572.

18. Wardlaw A, Larivee P, Eller J, Cockcroft DW, Ghaly L, Harris AG: Efficacy and safety of mometasone furoate dry powder inhaler vs fluticasone propionate metered-dose inhaler in asthma subjects previously using fluticasone propionate. Ann Allergy Asthma Immunol 2004, 93(1):49-55.

19. Bernstein DI, Berkowitz RB, Chervinsky P, Dvorin DJ, Finn AF, Gross GN, Karetzky M, Kemp JP, Laforce C, Lumry W, et al: Dose-ranging study of a new steroid for asthma: mometasone furoate dry powder inhaler. Respir Med 1999, 93(9):603-612.

20. Nayak AS, Banov C, Corren J, Feinstein BK, Floreani A, Friedman BF, Goldsobel A, Gottschlich GM, Hannaway PJ, Lampl KL, et al: Once-daily mometasone furoate dry powder inhaler in the treatment of patients with persistent asthma. Ann Allergy Asthma Immunol 2000, 84(4):417-424.

21. Kemp JP, Berkowitz RB, Miller SD, Murray JJ, Nolop K, Harrison JE: Mometasone furoate administered once daily is as effective as twicedaily administration for treatment of mild-to-moderate persistent asthma. J Allergy Clin Immunol 2000, 106(3):485-492.

22. Noonan M, Karpel JP, Bensch GW, Ramsdell JW, Webb DR, Nolop KB, Lutsky BN: Comparison of once-daily to twice-daily treatment with mometasone furoate dry powder inhaler. Ann Allergy Asthma Immunol 2001, 86(1):36-43.

23. Bensch GW, Prenner B, Berkowitz R, Galant S, Ramsdell J, Lutsky B: Oncedaily evening administration of mometasone furoate in asthma treatment initiation. Ann Allergy Asthma Immunol 2006, 96(4):533-540.

24. Karpel JP, Busse WW, Noonan MJ, Monahan ME, Lutsky B, Staudinger H: Effects of mometasone furoate given once daily in the evening on lung function and symptom control in persistent asthma. Ann Pharmacother 2005, 39(12):1977-1983. 
25. D'Urzo A, Karpel JP, Busse WW, Boulet LP, Monahan ME, Lutsky B,

Staudinger $\mathrm{H}$ : Efficacy and safety of mometasone furoate administered once-daily in the evening in patients with persistent asthma dependent on inhaled corticosteroids. Curr Med Res Opin 2005, 21(8):1281-1289.

26. Storms W: Clinical trials: are these your patients?. J Allergy Clin Immunol 2003, 112(5 suppl):S107-S111.

27. Bayliss MS, Espindle DM, Buchner D, Blaiss MS, Ware JE: A new tool for monitoring asthma outcomes: the ITG Asthma Short Form. Qual Life Res 2000, 9(4):451-466.

28. ZuWallack R, Adelglass J, Clifford DP, Duke SP, Wire PD, Faris M, Harding SM: Long-term efficacy and safety of fluticasone propionate powder administered once or twice daily via inhaler to patients with moderate asthma. Chest 2000, 118(2):303-312.

29. Busse W, Raphael GD, Galant S, Kalberg C, Goode-Sellers S, Srebro S, Edwards L, Rickard K: Low-dose fluticasone propionate compared with montelukast for first-line treatment of persistent asthma: a randomized clinical trial. J Allergy Clin Immunol 2001, 107(3):461-468.

30. Pauwels RA, Pedersen S, Busse WW, Tan WC, Chen YZ, Ohlsson SV, Ullman A, Lamm CJ, O'Byrne PM: Early intervention with budesonide in mild persistent asthma: a randomised, double-blind trial. Lancet 2003, 361(9363):1071-1076

31. Jonasson G, Carlsen KH, Mowinckel P: Asthma drug adherence in a long term clinical trial. Arch Dis Child 2000, 83(4):330-333.

32. Rand C, Bilderback A, Schiller K, Edelman JM, Hustad CM, Zeiger RS: Adherence with montelukast or fluticasone in a long-term clinical trial: results from the mild asthma montelukast versus inhaled corticosteroid trial. J Allergy Clin Immunol 2007, 119(4):916-923.

33. Horne R, Weinman J: Self-regulation and self-management in asthma: exploring the role of illness perceptions and treatment beliefs in explaining non-adherence to preventer medication. Psychology and Health 2002, 17(1):17-32.

34. Boulet LP: Perception of the role and potential side effects of inhaled corticosteroids among asthmatic patients. Chest 1998, 113(3):587-592.

35. Horne R, Price D, Cleland J, Costa R, Covey D, Gruffydd-Jones K, Haughney J, Henrichsen SH, Kaplan A, Langhammer A, et al: Can asthma control be improved by understanding the patient's perspective?. BMC Pulm Med 2007, 7:8.

\section{Pre-publication history}

The pre-publication history for this paper can be accessed here:http://www. biomedcentral.com/1471-2466/10/1/prepub

doi:10.1186/1471-2466-10-1

Cite this article as: Price et al:: Improved adherence with once-daily versus twice-daily dosing of mometasone furoate administered via a dry powder inhaler:

a randomized open-label study. BMC Pulmonary Medicine 2010 10:1.

\section{Publish with BioMed Central and every scientist can read your work free of charge}

"BioMed Central will be the most significant development for disseminating the results of biomedical research in our lifetime. " Sir Paul Nurse, Cancer Research UK

Your research papers will be:

- available free of charge to the entire biomedical community

- peer reviewed and published immediately upon acceptance

- cited in PubMed and archived on PubMed Central

- yours - you keep the copyright
BiolMedcentral 